\title{
Learning at the Science Museum. A study on the public's experiences with different types of visit at the Museo Nazionale della Scienza e della Tecnologia "Leonardo da Vinci" in Milan, Italy
}

\section{Matteo Villa}

\section{Abstract}

Keywords

Introduction
This study aims to investigate whether different types of museum visits have specific ways to influence the visitors' experience and learning. Three types of museum visits as offered by the Museo della Scienza e della Tecnologia "Leonardo da Vinci" in Milan, Italy were taken into consideration: free tour, guided tour, and lab. The study involved visitors over 25 years of age. The way visits took place, the visitors' learning and experiences were investigated based on evidence collected using methods such as Personal Meaning Mapping and observation.

Our study has revealed that the outcomes of the visits vary in terms of visitor experience and depth of knowledge on the main subject. No significant differences were found as concerns the level of attention (visitors proved to be attentive while at the museum regardless of the type of visit).

Informal learning; Science centres and museums

Modern theories define the act of learning not as an abstract process, but as one that is embedded in a real context, in which mental actions are as important as physical ones. Learners can use different techniques to approach experience and process the information acquired, in accordance with the personal learning method that seems most fitting to them [Cassels, 1992; Fleming, 2001; Gardner, 1987]. In addition, learning is not simply conceived as an acquisition of new notions, but more in general it involves developing new skills, understanding, promoting values, ideas and feelings, and an ability to reflect [Hooper-Greenhill, 2000].

In line with this complex definition of the learning processes, many contemporary museums offer a multifaceted variety of experiences for visitors to enjoy the learning materials and contents exhibited in their halls [Merzagora and Rodari, 2011]. Visitors can roam freely, exploring the rooms exhibiting the items in the showcases, the captions, the interactive installations. Or else, they can listen to the explanations of an expert during a guided tour. Or they can even participate in lab sessions focusing on engagement in shared activities.

Considering that visits from the public obviously are among the fundamental activities of a museum, in the past few years the visitors' experiences have become 
the subject of investigation within informal education institutions. However, there are less empirical studies on the public's experiences at exhibitions than theoretical studies on museums [Kirchberg and Tröndle, 2012].

Authors such as Falk and Dierking investigated the outcomes of a visit in terms of learning [Falk and Dierking, 2000]. In other instances, the study investigated how visitors handle the path of their visit and where they direct their attention when they can freely roam throughout the museum halls [Bitgood, 2011].

Rather than focusing on the outcomes of a specific visit - a standard single way to experience the exhibitions - this study aims to simultaneously address the various ways a visit can be carried out. The purpose is to compare the methods by which a museum can offer its contents to the public, and to study how the perception of a museum visit can change based on its approach

Raising awareness on the mechanisms and the specific outcomes of each method to implement a visit may provide interesting food for thought to those in charge of planning the experience to be offered to visitors. Being aware of the specific processes each type of visit implies may help them devise a more effective way to convey the message a museum wants to give to its visitors.

Research aims

This study aims to establish whether museum visitors learn different things based on the type of experience they have: either a free tour, a guided tour, or a lab. Do such types of visit have any specificities, or intrinsic characteristics in the way they stimulate the experience of museum visitors?

The complex experience during a museum visit was analysed along three dimensions, which have provided the grounds to compare the different outcomes of the visit. The first dimension concerns the type of experience the visitors had: did the visit impress them in emotional terms? Did the museum tour only provide sciolistic information? Was the visitor struck by the social component in the interaction with the others? Or were the historical artefacts what actually hit them?

The second dimension concerns how the visit increased the visitors' depth of knowledge (DOK) on the subject of the exhibition.

The third dimension concerns the level of attention shown by the participants throughout the activities.

\section{Methods}

Instruments

Three instruments were used to evaluate the visitors' experiences and to record how the visit was carried out. They were chosen so as to report any previous knowledge possessed by the subjects, how the visit developed and what the outcomes were. Those aspects provide elements that are useful to investigate the dimensions identified to make a comparison among the approaches to a museum visit: type of experience, depth of knowledge, level of attention. 
The instruments used were the following:

- Personal Meaning Mapping.

The Personal Meaning Map (PMM) was used to record the change in a subject's perception and knowledge after a visit, as well as the type of impressions left by it, what elements impressed the visitor the most; therefore the PMM was used to investigate the dimensions "depth of knowledge" and "type of experience".

The PMM is an instrument to test out learning in an efficient, flexible and reliable way in free-choice learning contexts as devised by John Falk [Falk, 2003]. According to this approach, individuals are asked to write down on blank paper words, ideas, pictures, sentences, or thoughts that come to their mind in relation to either a concept or a word, before and after the visit. The key word is written at the centre of the page and circled, and it represents the key issue of the visit. The PMM was used as it spurs the subjects to express their thoughts without restrictions.

- Observation.

While the subjects were visiting the museum, we observed and recorded on our diaries their behaviours and activities, and where they stopped to contemplate or interact with an exhibit or to read a label, as well as the specification of the time elapsed. Such data allowed us to record the behaviours revealing the level of attention the visit was able to produce in the subjects.

- Questionnaire.

In order to collect demographics on the subjects involved in the study, at the end of their visit, individuals were asked to complete a questionnaire.

Settings

Research was conducted at the Museo della Scienza e della Tecnologia "Leonardo da Vinci" in Milan, one of the most important science museums in Italy, which offers to visitors three types of visits: free tours, guided tours, and labs. Two settings were taken into account for each type of visits, so as to diversify the paths of visit and therefore to make up for the fact that the outcomes are obviously influenced by the specific features of each exhibition. In total, research was carried out on six exhibitions:

- Free tour: Rail Transport Historical Collection and Space Permanent Exhibition

- Guided tours: "Rail and Water Transport" and "Space: yesterday, today, tomorrow"

- Labs: "Leonardo: Ingenious Machines" and the activities in the Tinkering Zone

The historical section devoted to rail transport includes a pavilion displaying one hundred years of evolution in rail transport starting from the second half of the 
$19^{\text {th }}$ century, and exhibiting heavy locomotives. In the Space section, visitors can find ancient and modern instruments for astronomic observation and research, as well as a number of interactive installations focusing on space. Such two areas were chosen as they represent two extremely different types of exhibition: the former is a traditional exhibition where only historical items are on display, whereas the latter features exhibits integrated with more modern media, such as videos, interactive installations, videogames.

During guided tours through such two sections, visitors can learn more about specific aspects of the exhibits thanks to the explainers.

Unfortunately, at the Museo della Scienza there are not interactive labs on space and rail transport (which would have allowed us to select a common subject of investigation across the three types of visit). Therefore, in choosing the interactive labs - as with the visits above - we decided to give priority to activities having different characteristics, though belonging to the same category.

The "Ingenious Machines" interactive lab gives participants a chance of a close encounter with the machines designed by Leonardo and to see their operation, at the presence of an explainer leading the various steps of the activity. On the other hand, in the Tinkering Zone visitors are invited to combine instruments and materials in an original way, in line with a theme that inspires the activity time after time, inventing, experimenting, and playing. In this case, members of staff only play a supporting role, and visitors carry out the activities quite independently.

\section{Sample}

Research focused on adult visitors. "Adults" also included those that had concluded - or were about to conclude - a typical university curriculum. This means the test was carried out on visitors aged 25 or more.

The sample was distributed among the types of visit as illustrated in table 1.

Table 1. Distribution of the number of subjects by type of visit.

\begin{tabular}{|l|l|l|l|l|l|}
\hline Free tour & \multicolumn{4}{|l|}{ Guided tour } & Lab \\
\hline $\begin{array}{l}\text { Rail } \\
\text { transport }\end{array}$ & Space & $\begin{array}{l}\text { Rail } \\
\text { transport }\end{array}$ & Space & Leonardo & Tinkering \\
\hline 15 Subjects & 15 Subjects & 15 Subjects & 15 Subjects & 15 Subjects & 15 Subjects \\
\hline \multicolumn{2}{|l|}{ TOT: 30 Subjects } & \multicolumn{4}{|l|}{ TOT: 30 Subjects 30 Subjects } \\
\hline
\end{tabular}

In total, there were 90 subjects involved. The study was carried out over a period from November 2014 to February 2015.

The distribution of the sample by age is shown in figure 1, whereas distribution by gender is shown in figure 2 .

\section{Procedure}

Before visitors started their specific path, they were asked to write down any ideas, concepts, impressions and knowledge they had in relation to the word at the centre of the PMM. 


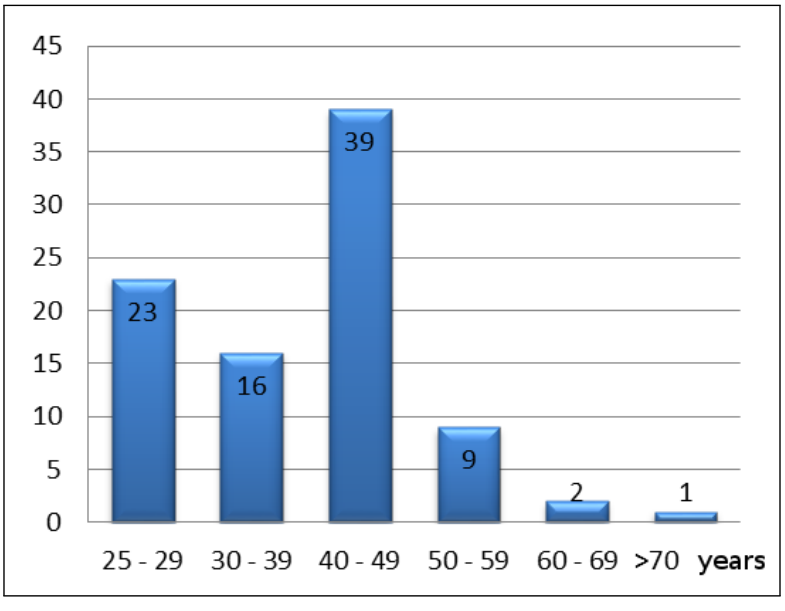

Figure 1. Visitors interviewed, by age $(n=90)$.

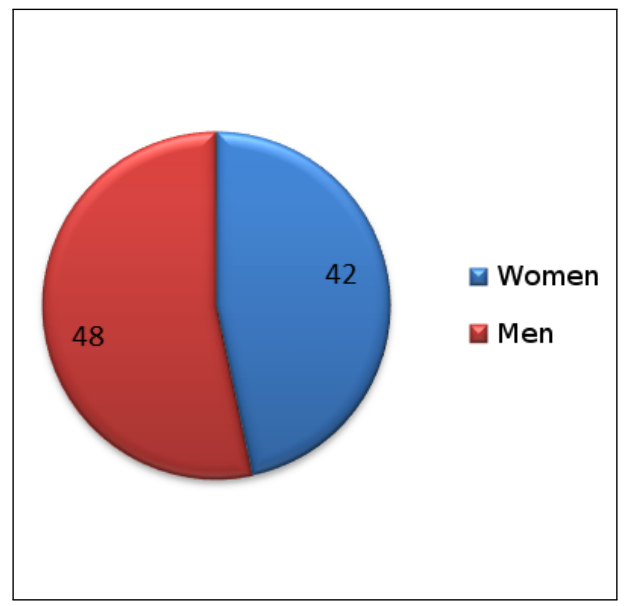

Figure 2. Visitors involved, by gender $(n=90)$.

Four types of maps were used. Each one of them had a word corresponding to the key issue of the visit the visitor was about to start. The four words used were: "Rail transport" (for free and guided tours through the rail transport pavilion), "space" (for free and guided tours through the space section), "Leonardo da Vinci" (in the maps used for the "Ingenious Machines" laboratory) and "Inventing" (in the maps used for the activities of the Tinkering Zone). After the initial PMM step, visitors could start their visit, during which observation was carried out. At the end, visitors were asked to use the same maps as before to write down what their visits had given them, in terms of: reflections, impressions, new knowledge and any remarks regarding what they had previously written (still focusing their minds on the key issue represented by the key word). The collection of data regarding visitors was completed with a questionnaire on demographics.

\section{Analysis of the data}

In order to reach the aim of the investigation, and to compare the visitors' experiences during types of visit that are so different, we built a grid to organise the corpus of information acquired through the PMMs and the observation reports, based on the three dimensions defined above, i.e. type of experience, depth of knowledge (DOK) on the subject of the visit, and level of attention. To define each of the three specific elements the analysis focused on, a list of parameters was identified drawing on the literature available.

The information collected through the PMMs (i.e. the ideas expressed by the visitors on the subject of the visit) represented the "type of experience" and the "depth of knowledge". The first aspect was divided into four options: object experiences, cognitive experiences, introspective experiences and social experiences [Pekarik, Doering and Karns, 1999], categories defined in table 2. The depth of knowledge and the commentaries by the visitors were analysed based on a four-level categorisation: recall, concept, strategic thinking and extended thinking [Webb et al., 2005], as defined in table 3.

Falk himself proposed an analysis protocol for the PMM [Falk, 2003]. However, that mainly focuses on the cognitive aspect of the experience. Therefore, in order to 
interpret the content of the maps, we opted for the application of categorisations able to appreciate the visit in a broader perspective.

Table 2. Type of experience subjects have during their visits [Pekarik, Doering and Karns, 1999].

\begin{tabular}{|c|c|}
\hline \multirow[t]{5}{*}{ Object experience } & Seeing "the real thing" \\
\hline & Seeing rare/un common/valuable objects \\
\hline & Being moved by beauty \\
\hline & Imagining what owning this type of objects may be like \\
\hline & Carrying on with my professional development \\
\hline \multirow[t]{2}{*}{ Cognitive experiences } & Gaining information or knowledge \\
\hline & Enriching understanding \\
\hline \multirow[t]{5}{*}{ Introspective experiences } & Imagining different places and times \\
\hline & Reflecting on the meaning of what I was seeing \\
\hline & $\begin{array}{l}\text { Reminiscing my journeys/the experiences of my life/other } \\
\text { memories }\end{array}$ \\
\hline & Perceiving a spiritual connection \\
\hline & Perceiving a sense of belonging and connection \\
\hline \multirow[t]{2}{*}{ Social experiences } & Spending time with friends/family/other people \\
\hline & Seeing my children learning new things \\
\hline
\end{tabular}

Table 3. Learners' depth of knowledge on the main subject [Webb et al., 2005].

\begin{tabular}{|l|l|l|}
\hline Level & Learner's actions & Key actions \\
\hline $\begin{array}{l}\text { Level 1: } \\
\text { Recall }\end{array}$ & $\begin{array}{l}\text { Requires the recall of informa- } \\
\text { tion, such as a fact, definition, } \\
\text { term, or a simple procedure. }\end{array}$ & $\begin{array}{l}\text { List, Tell, Define, Classify, } \\
\text { Identify, Name, State, Write, } \\
\text { Place }\end{array}$ \\
\hline $\begin{array}{l}\text { Level 2: } \\
\text { Concept }\end{array}$ & $\begin{array}{l}\text { Involves mental skills, concept } \\
\text { or processing beyond reprodu- } \\
\text { cing a response. }\end{array}$ & $\begin{array}{l}\text { Estimate, Compare, Organise, } \\
\text { Interpret, Modify, Make Pre- } \\
\text { dictions, Establish Cause/Effect } \\
\text { Relations, Summarise }\end{array}$ \\
\hline $\begin{array}{l}\text { Level 3: } \\
\text { Strategic Thinking }\end{array}$ & $\begin{array}{l}\text { Requires reasoning, planning, } \\
\text { using evidence, and a higher } \\
\text { level of thinking. }\end{array}$ & $\begin{array}{l}\text { Criticise, Formulate, Speculate, } \\
\text { Build, Review, Investigate, Dif- } \\
\text { ferentiate, Compare }\end{array}$ \\
\hline $\begin{array}{l}\text { Level 4: } \\
\text { Extended Thinking }\end{array}$ & $\begin{array}{l}\text { Requires complex reason- } \\
\text { ing, experimental design and } \\
\text { planning, development and } \\
\text { thinking. Cognitive effort is } \\
\text { more demanding, and learners } \\
\text { have to make connections } \\
\text { within and among the domains } \\
\text { of the subjects. }\end{array}$ & $\begin{array}{l}\text { Apsign, Connect, Synthesise, } \\
\text { ate, Try }\end{array}$ \\
\hline
\end{tabular}

The PMMs contained ideas on the key word corresponding to the subject of the visit. Each of those ideas was assigned to a category of experience and was given a DOK level.

By way of illustration, below are a few examples of interpretation and sketches of the visitors' ideas recorded on the maps. 
The statement in figure 3 was considered to be "cognitive" (as it recalls a piece of information, a notion), and was given DOK level n. 1 (Recall), as it is a simple reminiscence associating a word to its definition.

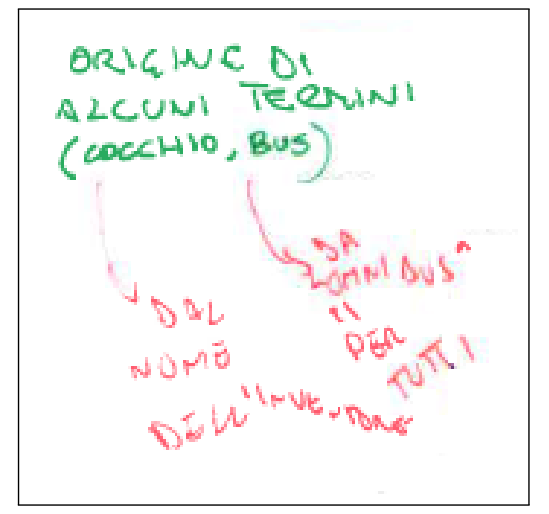

Origin of some words $\left(\right.$ cocchio $^{1}$, bus $\left.^{2}\right)$

${ }^{1}$ (carriage) From the name of the inventor

${ }^{2}$ From "omnibus", meaning for everyone

Figure 3. PMM: “Rail Transport” — Guided tour.

The evidence in figure 4, on the other hand, is an example of a "social" type of statement: it shows how the subject was impressed by watching the children learn, becoming engaged in the activity. Considering that the expression of the concept is also matched by a personal remark, this statement was given a DOK level n. 2 (Concept).

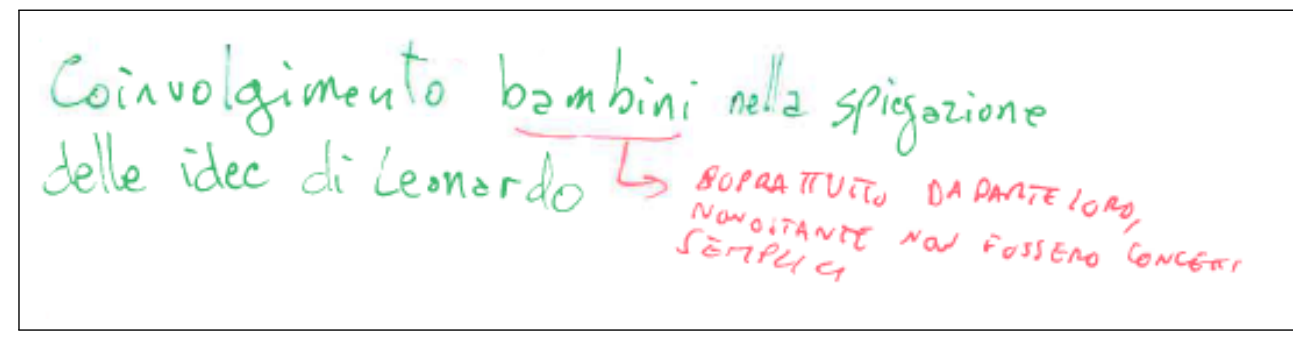

Engagement of children in the explanation of Leonardo's ideas Especially the children, although it was not simple concepts

Figure 4. PMM: "Leonardo da Vinci" — Lab.

The evidence in figure 5 represents a case of object experience, as the visitor said he or she was impressed by the beauty of locomotives. The subject not only defined the locomotives "beautiful", but he or she connoted more precisely this aspect by correlating it to the dimension of "ancient". Also this evidence was given a DOK level n. 2.

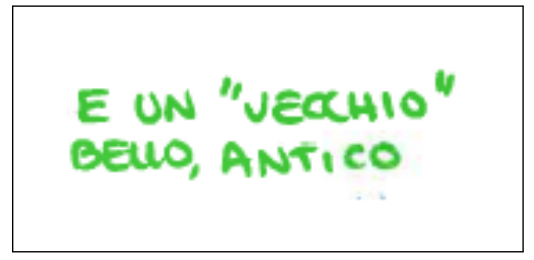

It's a beautiful, ancient type of "old things"

Figure 5. PMM: “Rail Transport” — Guided tour.

The evidence in figure 6 carries with it two aspects connoting it as introspective: in the first part, the visitor expresses a reflection on the sense emerging from what he 
or she observed, while in the second part he or she refers to an emotional type of experience. The subject expressed conclusions developing a critical thought, and this places the evidence within the $3^{\text {rd }}$ DOK level (Strategic Thinking).

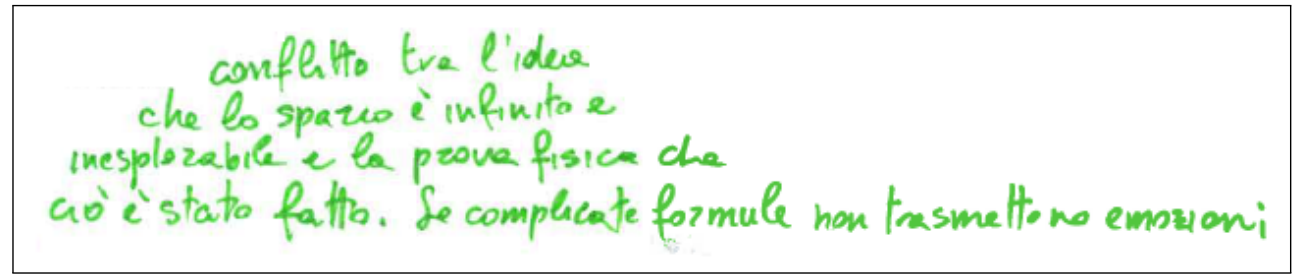

There's conflict between the idea that space is infinite and inexplorable and the physical evidence that it was actually done. If complicated, formulas do not convey emotions

Figure 6. PMM: "Space" — Free tour.

On the other hand, the information collected through observation was interpreted according to a categorisation inspired to Bitgood's work [Bitgood, 2010], as reported in table 4 .

Table 4. Level of attention shown by visitors [Bitgood, 2010].

\begin{tabular}{|l|l|}
\hline Level of attention & Indicators \\
\hline Distraction & $\begin{array}{l}\text { - A distance too far to listen } \\
\text { - Using the phone/smartphone for a prolonged period of time } \\
\text { - Not participating in the activity }\end{array}$ \\
\hline Focus & $\begin{array}{l}\text { - Observing the exhibits for a few seconds } \\
\text { - Touching briefly the exhibits }\end{array}$ \\
\hline Engagement & $\begin{array}{l}\text { - Reading the labels } \\
\text { - Discussing the contents } \\
\text { - Expressing feelings }\end{array}$ \\
\hline
\end{tabular}

The plan of our research

Figure 7 and figure 8 summarise in two diagrams the plan of our research project.

As each PMM is uniquely constructed in a very personal way, the number of statements providing information on "type of experience" and "DOK" was calculated out of the total number of statements contained in each map (which differs every time). This allowed us to make a quantitative comparison across different maps and to translate it into pie charts. At the same time, the level of attention was given a visual representation by calculating the time spent at a specific attention level in relation to the total duration of the visit.

\section{Type of experience}

The following pie charts show how the types of visit actually elicit a different type of experience in visitors. This was found thanks to the comments left by visitors on their maps after the visits. 


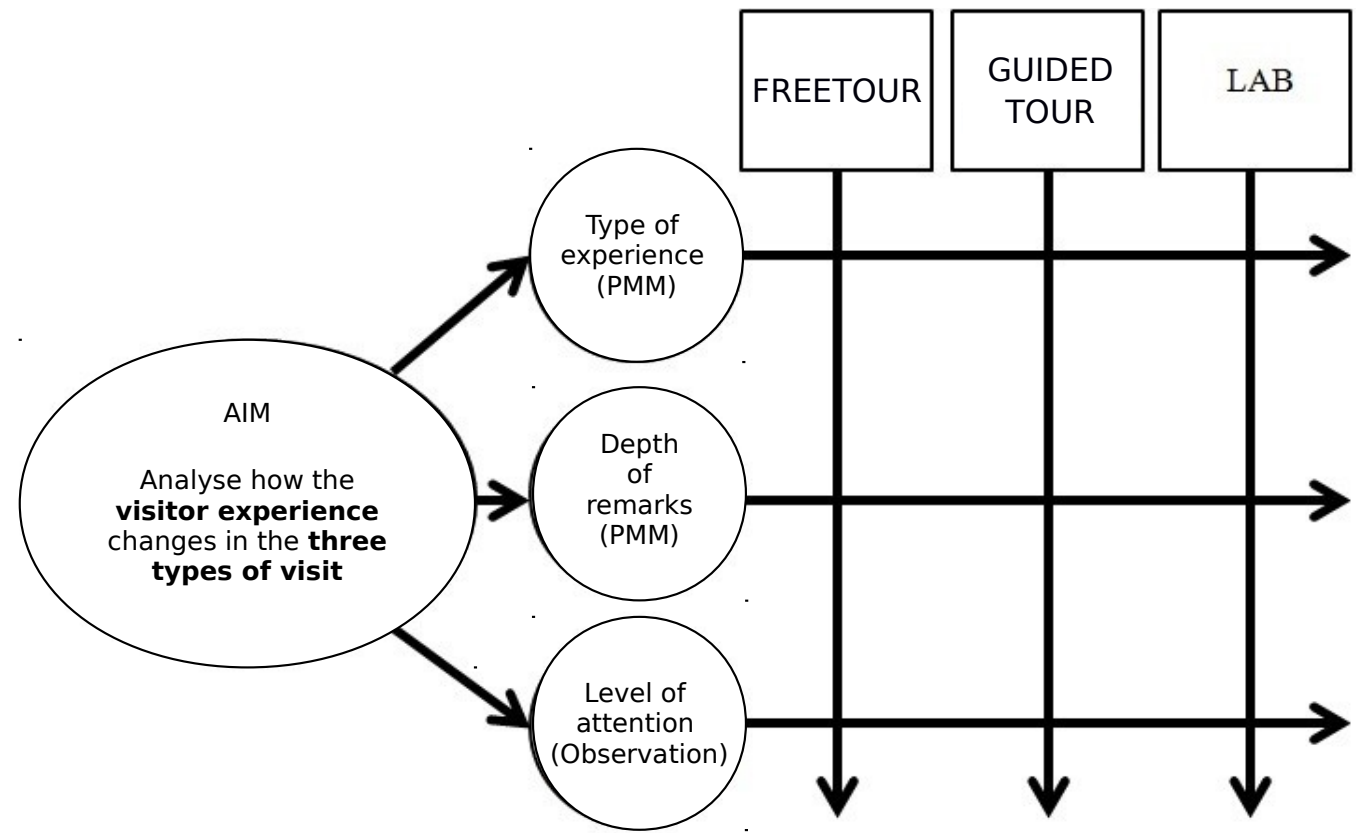

Figure 7. Research plan: aims.

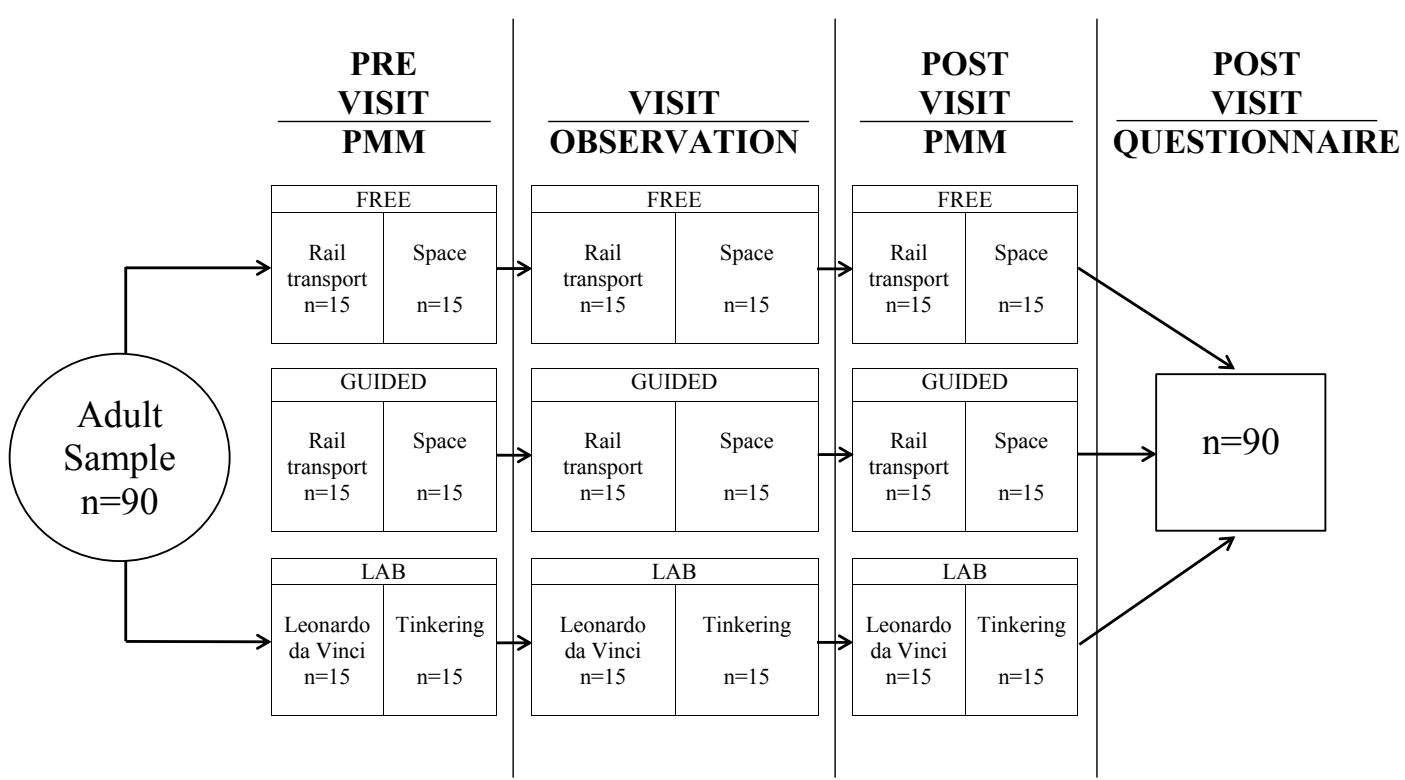

Figure 8. Research plan: sample, settings and instruments.

In the free tour (Figure 9) and in the guided tour (Figure 10), social experiences are basically missing. It does not mean that people do not interact during the tour (on the contrary, observation has shown visitors constantly influence one another, especially during free tours), but when they are asked to express what was left by their visit, subjects do not seem to be aware of that aspect of their museum experience, whereas they were impressed by other aspects: how they developed their own path of visit on the one hand (free tour), the guide's speech on the other (guided visit). The situation differs with the lab (Figure 11): during this type of activity, the explainer often draws the attention towards what the children in the visit group are doing (usually, in "Ingenious Machines" only the youngest ones 
actually engage in the practical activity), who are engaged in a very specific activity. When subjects have to comment on the visit in their PMMs, one of the aspects that actually left an impression on them is having witnessed the learning process of their children (usually, evidence on social experiences was focused on children, for example: "In order to understand how pulleys work, I've thought about my son, who tried it", "Remarkable engagement of children in the explanation, although it was not simple concepts"). The social dimension is acknowledged as a fundamental factor in the development of the visit [Falk and Dierking, 1992; Falk and Dierking, 2000]. The way different types of visit can stimulate the interaction among visitors is worthy of future research attention. For example, research may focus on the difference between aware and unaware social interactions during the visit, and on how the strength of social interactions can influence the perception of the museum experience and the information learnt.

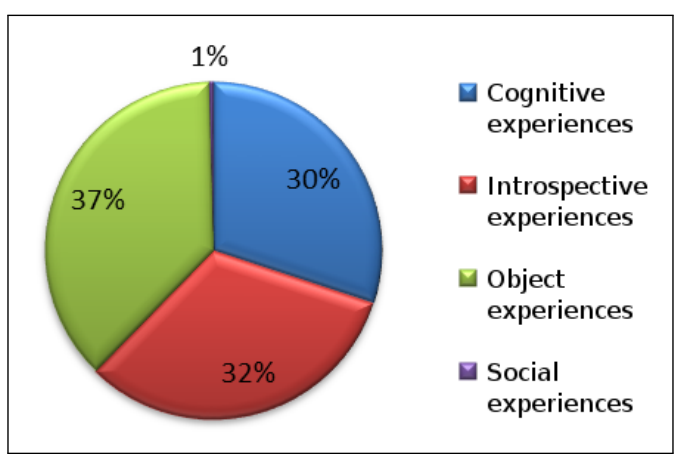

Figure 9. Types of experience (Free tour).

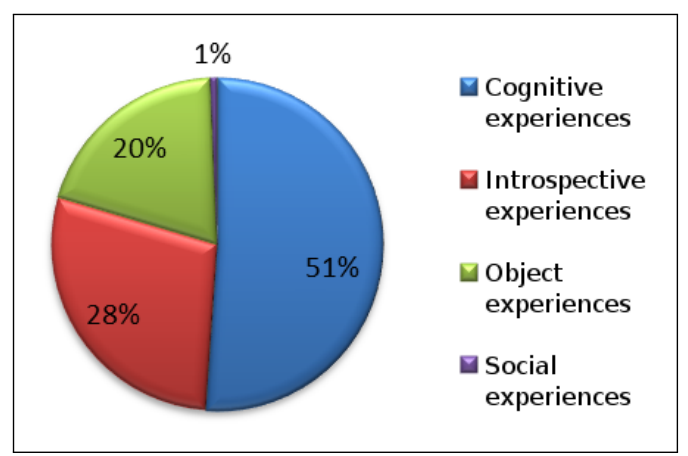

Figure 10. Types of experience (Guided tour).

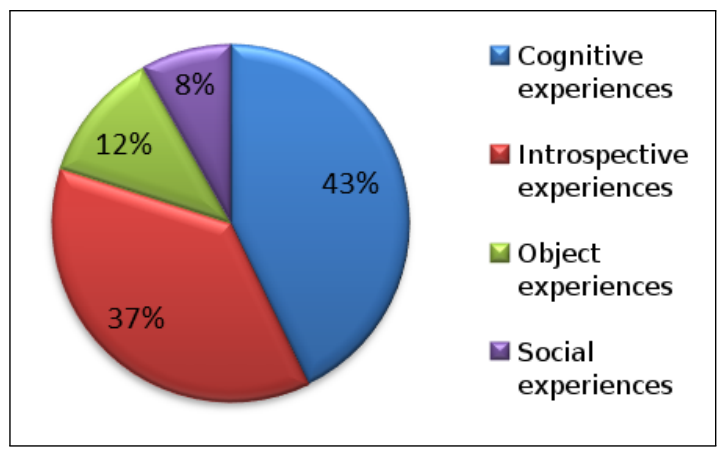

Figure 11. Types of experience (Lab).

Moving on to the other parameters of the experience, it should be noted that in free visits they are equally distributed. Evidently, this type of visit allows anyone to better shape their experience of a museum to their needs, and therefore the results are evenly distributed among the options (save for social experience, which was analysed above). This aspect shows that organising museum contents according to various communication approaches could be quite effective, as the public apparently happens to experience museums in many different ways.

In guided tours, introspective experiences and object experiences are close in terms of value, whereas cognitive experiences have a value that is twice as much. Although in guided tours the visitors walk through the same halls and see the same exhibits as the visitors in a free tour, cognitive evidence absolutely prevails in them. 
The verbal explanation of the exhibits apparently monopolised the visitors' attention. In fact, when asked to reminisce their visit in the PMMs, visitors recollected a lot of sciolistic information, including notions such as "Speed of the locomotives $130 \mathrm{~km} / \mathrm{h}$ ", "Only two horses to pull the tram" (from the rail transport visit), or more elaborated ones (from the space visit): "The ISS cost 100 billion, it's quite an investment in this period of economic recession", or "Learning how astronauts live in space made me think that it's not Earth controlling space, but it's space controlling Earth". Likewise, an opposite trend can be noted: when visitors are given more independence (on a free tour and in lab activities, in which the public is not "lectured"), they seem to acquire less notions related to the exhibition, whereas the experience is able to touch more their personal and emotional spheres.

Going back to the lab, it should be noted that cognitive experiences and introspective experiences have a similar value, whereas the value of object experience is significantly smaller. It is not surprising when you think that during lab activities visitors are not faced with exhibits in a typical way. Therefore, lab activities can be an effective complement to exhibitions focused on the presence of historical exhibits, thus stimulating an approach to museum contents in a different perspective.

\section{Depth of knowledge}

The following charts show a comparison between the depth of knowledge of visitors prior to and following their visits. Figure 12 shows pie charts referring to the total sample of visitors who have participated in the various types of visits at the Science Museum, which reveal that, at the end of their visits, there was an overall increase in the visitors' DOK on the subjects of the exhibitions.

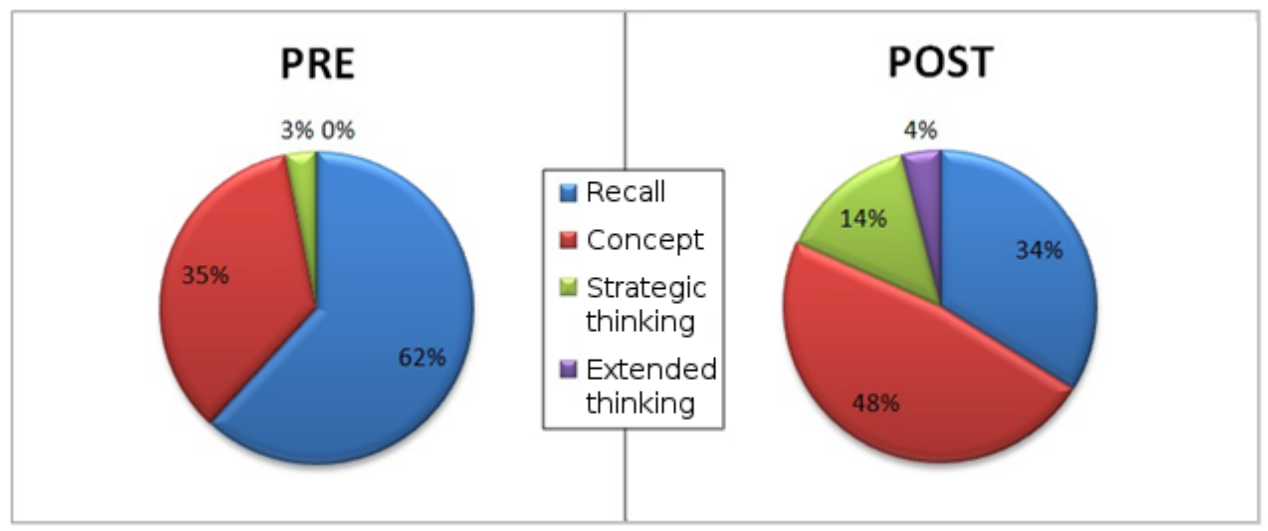

Figure 12. DOK: a comparison PRE- and POST-visit (Total sample).

The knowledge at the "recall" level - i.e. the most superficial one, belonging to the lowest level - went down from $62 \%$ to $34 \%$ in the PMMs. This means that the rest divides into types of knowledge belonging to a higher level. The main increase can be noted in the "concept" level (+13\%), which takes over the largest share in the pie chart after the visit. Also the categories "Strategic thinking" (+11\%) and "Extended thinking" $(+4 \%)$ show an increase. In conclusion, all the three levels indicating a deeper knowledge were marked by an increase, which in fact slowed down as the level was going up. Figures 13,14 and 15 show the results by type of visit. 


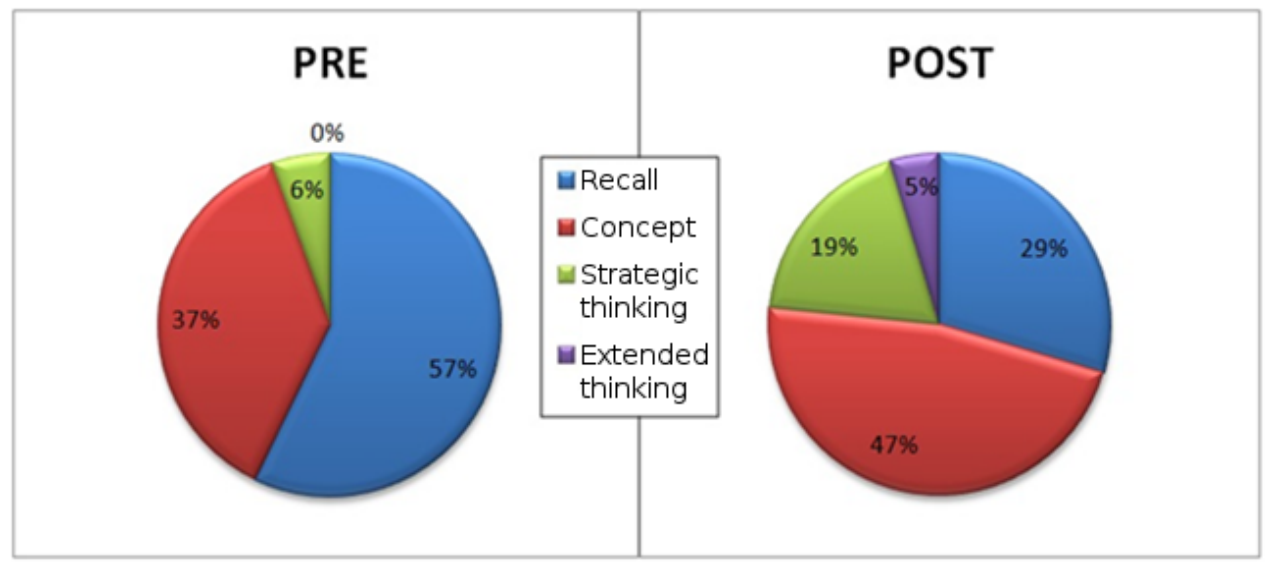

Figure 13. DOK: a comparison PRE- and POST-visit (Free tour).

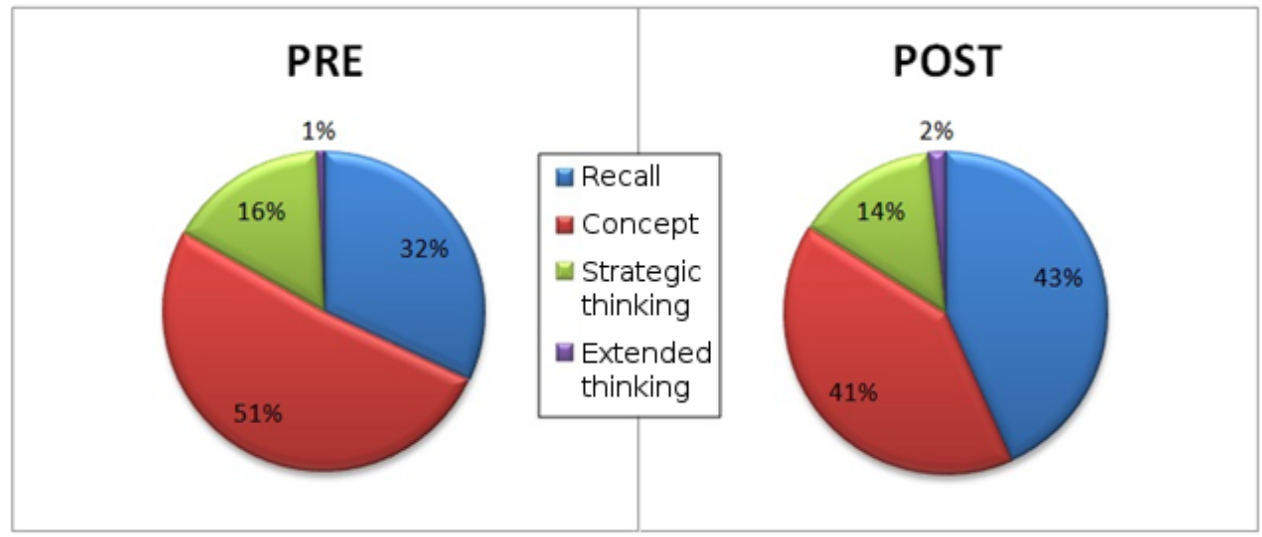

Figure 14. DOK: a comparison PRE- and POST-visit (Guided tour).

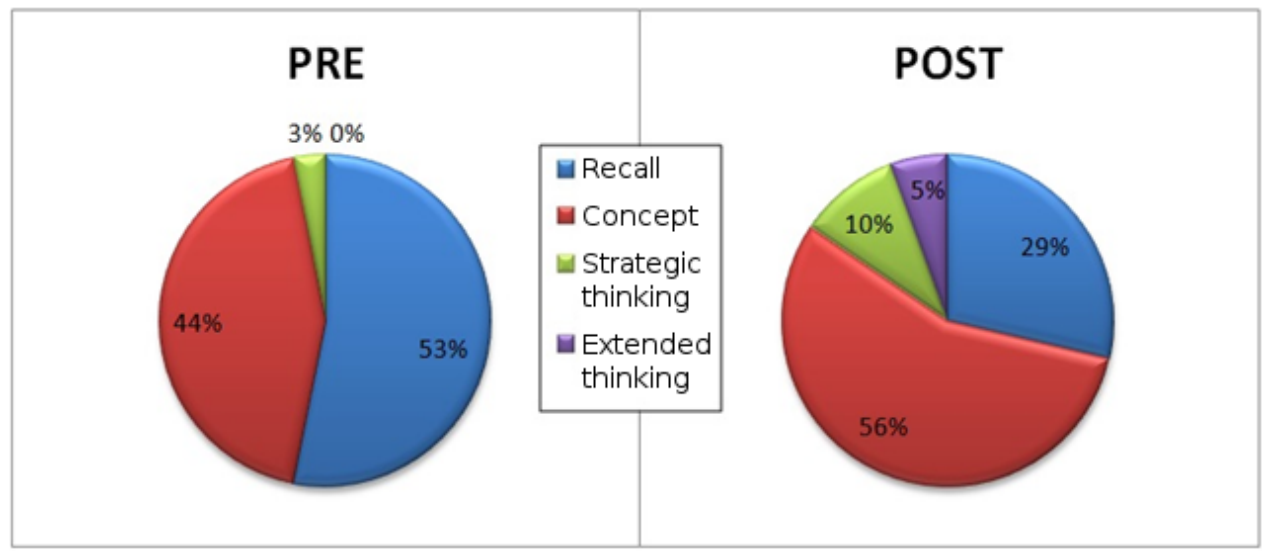

Figure 15. DOK: a comparison PRE- and POST-visit (Lab).

The results from the free tour and the lab (Figure 13 and figure 15 respectively) are not very different, whether you consider the final outcome or the initial step. In addition, they show a pie chart that follows the same trend as the total sample. On the other hand, the guided tour (Figure 14) is quite peculiar: it is the only case in which "Recall" stands out as the only share to increase to the detriment of the others. 
The charts on the type of experience showed that in guided tours there was a higher presence of cognitive experiences. Then, at the end of the guided tour, visitors may have memorised a larger quantity of notions during the visit, and when asked to complete the map, they most typically tend to recall what they have learned rather than processing their own thoughts. We refer to evidence such as: "steam locomotives from the 20s ran until the 50s", "I've learned the origin of the words 'cocchio' and bus", "I've learned the nickname Gamba de Legn" (rail transport visit), or "Overalls, satellites, helmets, lunar fragment", "Animals in space" (space visit).

In a certain sense, those who remember more information tend to make less efforts in extended thinking, for example synthesising, establishing comparisons, or developing other ideas that increase the depth of knowledge, according to the definition of DOK adopted. A higher DOK is observed in the evidence on the other visits, for example: "In order to learn, it is useful to behave like children again, cleaning your thinking from superstructures, yet drawing from experience", "What we produce is always imperfect $\checkmark$ acceptance, no judgment/experimentation, you learn from your mistakes" (Tinkering), "Once there was a constant and evident improvement, today everything's old and static" (Rail transport), "Before the visit, I didn't consider the human component, the emotions of exploration and the astronauts' courage" (Space).

\section{Level of attention}

Nearly throughout the activities, the visitors were engaged to a high level of attention, as shown in figure 16.

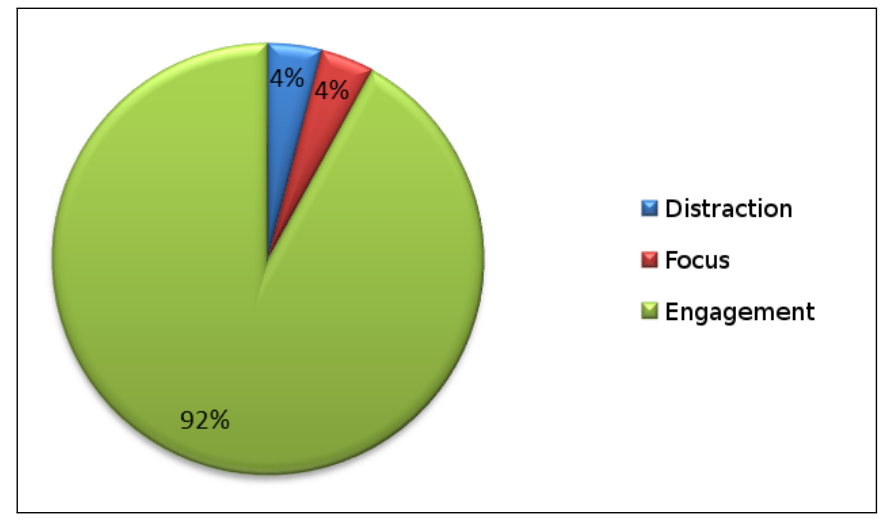

Figure 16. Level of attention (Total).

Also the pie charts referring to the types of visit (Figures 17, 18,19) show that the visitors' attention is captured to the highest level while they are in the museum. However, the study did not survey the quality of the attention shown. Therefore, there may be differences among the types of visit as they may make it harder to maintain a high level of attention. free tour and the lab tend to elicit more of a subjective-emotional type of experience. Introspective experiences, object experiences and social experiences - according to the definitions introduced by Pekarik, Doering a d Karns and 


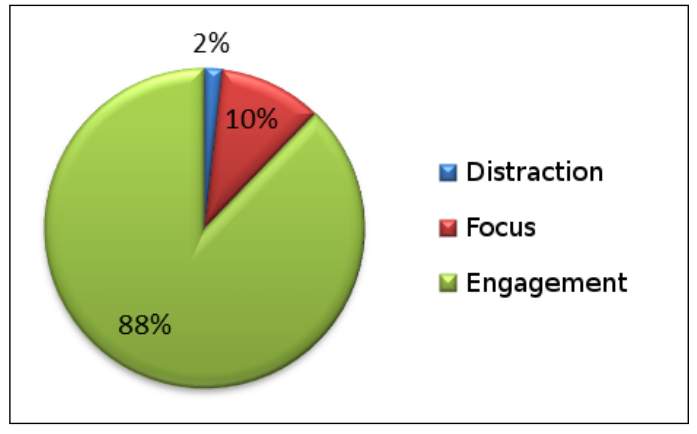

Figure 17. Level of attention (Free tour).

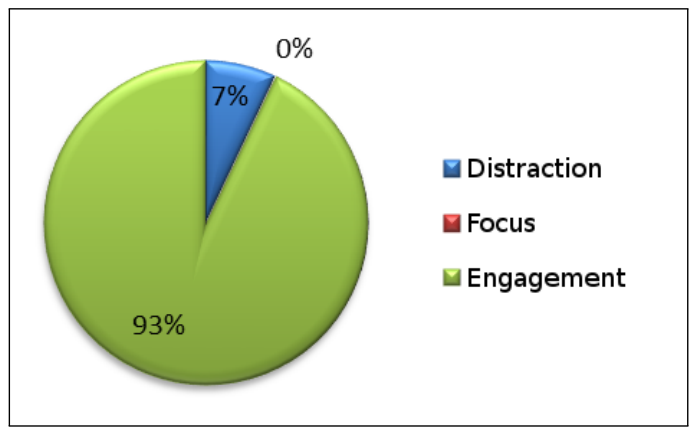

Figure 18. Level of attention (Guided tour).

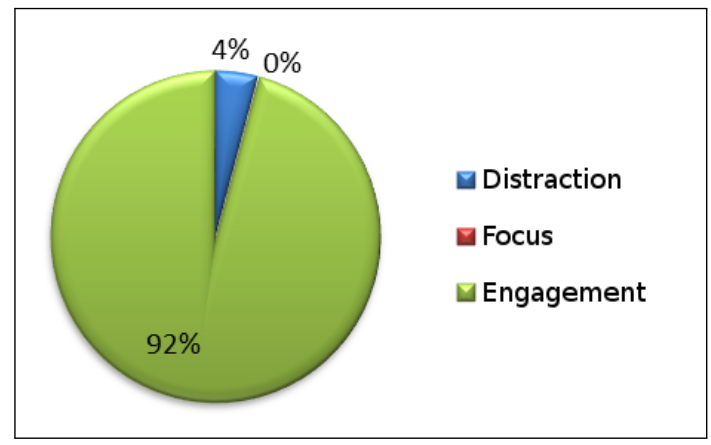

Figure 19. Level of attention (Lab).

quoted in table 2 - apparently share characteristics that place them all in a macro-category of a personal-emotional nature. Indeed, the three types of experiences all refer to an emotional or imaginative type of experience.

Introspective experience concerns the connection with the personal domain of the subject; object experience - although provoked by something external - activates in any case either an evocative force of imagination or the perception of a feeling; social experience concerns the pleasure, the empathy felt in watching someone else learn or in learning along with other people. At the opposite side there is cognitive experience, which concerns the realm of objective information increasing the level of education and understanding - a type of experience that was the most evident consequence to the participation in a guided tour.

The free tour and the labs emphasise the active role the visitor plays in building his or her experience at the museum. Considering the results in this perspective, what appears is that when the subject is freer to define his or her experience of the museum, the mere absorption of information gives way to the emotional dimension.

In addition, when it comes to stating what the visit at the exhibition left in them, the subjects involved in those two types of museum visits showed a higher DOK when reporting their ideas. The broader availability of information demonstrated at the end of the guided tours might have superseded more articulate personal thinking: indeed, data showed that immediate and superficial reminiscence was more frequent than the processing and assimilation of notions through personal interpretation. Future research may investigate whether the perception of the visit has changed after a certain amount of time by seeing what information or impressions have endured the most, to subsequently compare the effects of the types of visit in the long term. 
As concerns the issue of capturing the attention of visitors, it has emerged that the public shows concentration nearly throughout the visit, and this is true in all types of visit. Data do not allow for a more specific analysis to make a statement as to whether the engagement was pleasant and spontaneous, or actually forced and tiring, as the analysis was only aimed at establishing the level of attention, and not its quality. A further study on this point may reveal additional differences among free tour, guided tour and lab that could not emerge here.

This research also left out other aspects that could be further investigated in the future. Considering the composition of the public visiting museums, an important advancement would be made by adding the experience of younger people, as well as by refining the analysis of the adults' experience, separating the subjects whose experience was influenced by the interaction with their children from those who participated in adult groups.

The visit was analysed by focusing on three representative dimensions (type of experience, depth of knowledge, level of attention). However, the comparison could be outlined based on principles alternative to the ones used in this study. For example, the various ways to live the museum could be considered in the light of the definition of flow experience [Csikszentmihalyi, 1990], referring to the conditions of this particular state as a gauge of the difference in the types of visit.

Further investigation on the intrinsic characteristics of the types of visit may help design the communication of museum contents: knowing the weaknesses and strengths of each visit can be an opportunity to devise ways to offset any shortcomings when a museum visit is designed and proposed to the public.

A better awareness on this subject may help choose the most suitable medium for the message to be conveyed based on the goals: should awareness on a subject be raised among the public, so that the path of visit has to make it salient in emotional terms? Or do we intend to provide a large amount of information and disseminate a certain topic? Do we aim to stimulate debate among visitors? Or to encourage visitors to question their beliefs?

More in general, what the findings suggest is that the three types of visit are not merely different ways to convey the same message, to deal with the same topic. Each type of visit, with its specific features, is able to elicit a specific experiential dimension that builds the perception of the visit at the museum.

\section{Translated by Massimo Caregnato}

\section{References}

Bitgood, S. (2010). An attention-value model of museum visitors. Center for the Advancement of Informal Science Education.

- (2011). Social Design in Museums: The Psychology of Visitor Studies Volume One. Edinburgh, U.K.: MuseumsEtc.

Cassels, R. (1992). 'Mind, heart and soul: towards better learning in heritage parks'. New Zealand museums journal 22 (2), pp. 12-17.

Csikszentmihalyi, M. (1990). Flow: the psychology of optimal experience. New York, NY, U.S.A.: Harper \& Row. 
Falk, J. H. (2003). 'Personal meaning mapping'. In: Museums and creativity: A study into the role of museums in design education. Ed. by G. Caban, C. Scott, J. Falk and L. Dierking. Sydney, Australia: Powerhouse Publishing.

Falk, J. H. and Dierking, L. D. (1992). The museum experience. Washington, DC, U.S.A.: Whalesback Books.

- (2000). Learning from Museums: Visitor Experiences and the Making of Meaning. Walnut Creek, CA, U.S.A.: AltaMira Press.

Fleming, N. D. (2001). Teaching and learning styles: VARK strategies. Christchurch, New Zealand: N.D. Fleming.

Gardner, H. (1987). Formae mentis. Saggio sulla pluralità dell'intelligenza. Milan, Italy: Feltrinelli Editore.

Hooper-Greenhill, E. (2000). 'Communication and communities: Changing paradigms in museum pedagogy'. In: Museums of modern science. Nobel Symposium 112. Ed. by S. Lindqvist. Canton, MA, U.S.A.: Science History Publications, pp. 179-188.

Kirchberg, V. and Tröndle, M. (2012). 'Experiencing Exhibitions: A Review of Studies on Visitor Experiences in Museums'. Curator: The Museum Journal 55 (4), pp. 435-452. DOI: 10.1111/j.2151-6952.2012.00167.x.

Merzagora, M. and Rodari, P. (2011). La scienza in mostra. Musei, science centre e comunicazione. Milan, Italy: Bruno Mondadori.

Pekarik, A. J., Doering, Z. D. and Karns, D. A. (1999). ‘Exploring Satisfying Experiences in Museums'. Curator: The Museum Journal 42 (2), pp. 152-173. DOI: 10.1111/j.2151-6952.1999.tb01137.x.

Webb, N., Alt, M., Ely, R. and Vesperman, B. (2005). Web Alignment Tool (WAT) Training Manual. Madison, WI, U.S.A.: Wisconsin Center for Education Research.

Author

Matteo Villa earned a Master's Degree in Cognitive Science and Decision Making at the Università degli Studi di Milano, with a thesis about visitors' learning and experience at the Museo Nazionale della Scienza e della Tecnologia "Leonardo da Vinci" in Milano. He collaborate in research projects in the same institution. E-mail: villa@museoscienza.it.

\section{How to cite}

Villa, M. (2016). 'Learning at the Science Museum. A study on the public's experiences with different types of visit at the Museo Nazionale della Scienza e della Tecnologia "Leonardo da Vinci" in Milan, Italy". JCOM 15(04), A01_en. 